\title{
A Utilização de Recursos Naturais pelos Povos \\ Indígenas: Auto-Regulação, Participação e Normas \\ Impostas na Bolívia, Peru e Brasil
}

Geoffroy Filoche $e^{(*)}$

\section{INTRODUÇÃO}

O etnodesenvolvimento, tal como ele é ordenado pelo direito internacional, pode ser definido como um desenvolvimento adaptado, selecionado e controlado pelos povos indígenas, na maior parte de seus elementos.

Com efeito, a aplicação prática do desenvolvimento sustentável pode implicar no reconhecimento de direitos e de garantias em benefício dos povos autóctones, tendo em vista o desejo da sociedade de utilizar suas práticas e conhecimentos no que se refere à gestão ambiental. Mas, esta aplicação prática do desenvolvimento sustentável pode também limitar os direitos destes povos, da mesma forma como limita os direitos de todas as outras categorias da população.

Diferentes obstáculos podem emergir da imprecisão do direito positivo, em razão de uma compreensão superficial dos processos ecológicos e sociais, os quais supõe-se que o direito conheça, bem como da característica dialética dos objetivos deste direito, os quais oscilam entre a preservação e a hibridização culturais e entre a abertura econômica e a perpetuação das economias tradicionais.

Em princípio, o desenvolvimento sustentável não deve ser a única forma de legitimação, nem a única moldura aplicável ao etnodesenvolvimento. As fontes jurídicas que prescrevem uma certa autodeterminação não devem,

(*) Membro do Instituto de Pesquisa para o Desenvolvimento — IRD. E-mail:<geoffroyfiloche@yahoo.com>. Recebido em 22.1.07. Aprovado em 15.6.07. 
dessa maneira, ser ocultadas. Paralelamente, os indígenas não devem ser enquadrados nos moldes de vida sociais e econômicos que lhes permitiriam somente sobreviver em um mundo em interconexão e em mutação.

Neste ponto, a limitação dos direitos dos indígenas sobre seus recursos naturais deve ser decidida com a participação destes povos e esta limitação não poderá, de modo algum, impedi-los de promover um desenvolvimento adaptado e controlado, o que, provavelmente, garantirá um desenvolvimento durável.

Por esta razão, é imperativo a proposição de uma leitura construtiva dos direitos reconhecidos aos indígenas, os quais se inscrevem em um conjunto sedimentado e contraditório de textos normativos internacionais e nacionais. Tal revisão deve ser feita a partir de dois eixos. O primeiro diz respeito à autonomia reconhecida aos indígenas de utilizar e proteger os recursos naturais. Trata-se de estabelecer que o Estado reconheça os direitos mínimos mais intangíveis, assegurando aos povos o desfrute de certos recursos que lhes pertencem.

Porém, estes direitos básicos não são suficientes para permitir aos indígenas escolher a medida de sua evolução e de sua integração aos círculos políticos, culturais e econômicos contemporâneos, uma vez que, estes meios tendem a se tornar uma condição fundamental para a perpetuação destes povos, enquanto grupos distintos, e para sua inserção na comunidade nacional e internacional.

O segundo eixo de leitura dos direitos indígenas está relacionado com a participação destes povos na elaboração de normas (gerais e específicas) que regulem a utilização e proteção de recursos naturais. Trata-se de avaliar, em que medida, conjuntamente com outros atores, os indígenas podem elaborar os direitos circunstanciais que Ihes permitem estabelecer, do mais geral, ao mais concreto, os objetivos de um desenvolvimento sustentável, os procedimentos de arbitragem entre os diferentes interesses envolvidos, os limites, técnicas e a gestão da exploração de determinada espécie (vegetal ou animal).

Na Guiana Francesa, existe um engajamento em envolver os indígenas com a definição e a promoção do desenvolvimento sustentável. O desafio futuro será o de conciliar dois textos jurídicos: o decreto de $1987^{(1)}$ e a lei de orientação para os territórios ultramarinos ${ }^{(2)}$, dentro de um cenário no qual as atividades indígenas relacionam-se com o ambiente.

(1) Decreto n. 87-267, de 14 de abril de 1987 que prevê «modificação do Código de Domínio do Estado e relativo às concessões de domínio e outros atos do Estado na Guiana, com vistas à exploração ou à cessão de posses imobiliárias", JO de 16 de abril de 1987, p. 4316.

(2) Lei n. 2000-1207 de 13 de dezembro de 2000. 
Antes de mais nada, mesmo que "os direitos de uso coletivo"(3) sejam reconhecidos pelo poder municipal de maneira favorável aos Ameríndios, segundo o art. R. 170.56, do Decreto de 1987, existe uma restrição contida no art. R. 170.57:

"os direitos de uso mencionados [...] somente poderão ser exercidos com a reserva de aplicação dos dispositivos relativos à pesquisa e à exploração de substâncias minerais e das disposições relativas à proteção da natureza e das espécies animais e à defesa do ambiente [...]."

Esta norma deve ser lida à luz do art. 33 da lei de orientação para os territórios ultramarinos ${ }^{(4)}$ que obriga o Estado a considerar o valor das práticas e dos conhecimentos indígenas, principalmente com relação à gestão ambiental(5). Em uma formulação bastante próxima do art. 8 (j) da Convenção sobre Diversidade Bioológica, ele prevê que:

"o Estado e as comunidades locais estimulam o respeito, a proteção e a manutenção dos conhecimentos, inovações e práticas dos grupos indígenas, e das áreas moldadas de acordo com seu modo de vida tradicional, que contribuem para a conservação do meio natural e do uso sustentável da diversidade biológica."

O "texto aberto" (que trata de equilíbrios sociais e ambientais complexos e que precisa de uma regulamentação mais precisa) do art. 33 da Lei de orientação, entretanto, contrasta fortemente com o conteúdo fechado (limitações claras do direito de uso) do art. R. 170.57 do Decreto de 1987.

Por seu lado, os Estados amazônicos se utilizam de um técnica jurídica original: a substância dos direitos sobre os recursos naturais, relativos a sua apropriação, utilização e disposição, não são determinadas anteriormente pela legislação. O conteúdo destes direitos resultam de um diálogo entre o Estado e os indígenas, de acordo com as circunstâncias, e são validados dentro de "Plano de Utilização" local. Este plano permite, diante de

(3) Em nossa opinião, a questão do grau de apropriação dos recursos naturais jamais foi abordada, no que concerne aos ameríndios da Guiana Francesa. Parece-nos que o direito de uso assemelha-se a um direito de usufruto. De fato, de acordo com VIMON, J. Commentaire: les aspects civils de l'avant-projet de 1984. In: MARTRES, J.-P; LARRIEU, J. (Dir.). Coutumes et droit en Guyane. Economica, 1993. p. 127, "este direito de uso ainda é bastante fluído", e "seria melhor falar em direito de usufruto, considerando a concepção focada sobre as utilidades que o usufrutuário pode retirar da coisa, sem que haja antagonismo entre o usufrutuário e o nu-proprietário quanto aos seus direitos específicos". Neste momento, uma condição, relacionada às modalidades de exploração dos recursos naturais, foi implicitamente, porém, vagamente, estabelecida pelo direito. De fato, de acordo com o art. 578 do Código Civil "o usufruto é o direito de desfrutar das coisas através do qual se tem a propriedade da mesma forma que o proprietário, mas com a obrigação de conservar a substância da coisa".

(4) Nenhum Decreto regulamentador havia sido adotado.

(5) Ver KARPE, P. Y a-t-il encore des collectivités autochtones en Guyane française?: d'une méconnaissance à une indifférence (?) Contribution au 1er forum des élus amérindiens de Guyane (Awala-Yalimapo, 8 décembre 2001). Revue Juridique et Politique - Indépendance et Coopération, n. 2, p. 237, mai/août 2002. 
um determinado cenário, a utilização e/ou mistura das concepções indígenas relativas à propriedade, à ação sobre o ambiente e à maneira de dizer o direito, conciliando a estabilidade jurídica e a adaptação ao desenvolvimento ecológico e social.

A seguir, serão avaliadas duas questões. A primeira : qual o conteúdo dos direitos básicos intangíveis reconhecidos? E, em segundo lugar: como os indígenas podem participar da determinação das modalidades de exploração e dos limites sobre o que pode ser explorado?

\section{GARANTIA DOS DIREITOS BÁSICOS INTANGÍVEIS}

\section{A. Peru: garantias falhas e distinções inapropriadas}

A apropriação oficial das terras ancestrais pelos indígenas, em certos casos (terras com vocação agrícola), depende de atos de posse agrária (cultivo de todas as terras, segundo técnicas agrícolas modernas); em outras situações (terras com vocação florestal), depende da conformação dos indígenas às práticas estipuladas pelo contrato de concessão assinado com o Estado. Além disso, esta distinção "terras agrícolas/florestais" é uma aberração no contexto amazônico.

\section{Terras agrícolas}

Dentro das terras com vocação para a agricultura (desde reconhecidas como indígenas), os recursos naturais pertecem ipso facto aos indígenas (arts. 890, 891 e 892 do Código Civil), sem nenhuma condição suplementar. Porém, este direito não é completamente protegido.

De fato, após o art. 18 da Lei n. $26.821^{(6)}$, se as "comunidades nativas" (desde que elas tenham um título válido de suas terras) têm o direito preferencial de utilização sustentável dos recursos naturais, este direito se extingue em caso de "reserva expressa" do Estado ou de "direitos exclusivos ou excludentes", que podem ser de titularidade de terceiros.

\section{Terras com vocação florestal}

O estatuto jurídico dos recursos naturais situados nas terras florestais são ainda menos favoráveis aos indígenas ${ }^{(7)}$.

(6) Lei orgânica para a utilização sustentável dos recursos naturais de 10 de junho de 1997.

(7) No Peru, em nível nacional, somente $20 \%$ das terras são consideradas aptas para a agricultura, enquanto que $80 \%$ são divididas entre terras protegidas e aptas para a produção florestal. As terras florestais representam cerca de $40 \%$ do total das terras peruanas; entre elas, as Florestas 
Antes de mais nada, o art. 11 da Nova Lei das Comunidades Nativas (1978) dispõe que "a parte do território dos grupos nativos que correspondem às terras com vocação florestal lhe será cedida em uso e sua utilização será regida pela legislação que trata desta matéria". Segundo a legislação citada (Lei Florestal da Fauna Silvestre ${ }^{(8)}$ ), os recursos florestais e a fauna silvestre são de domínio público e não existe direito adquirido sobre estes recursos (art. $1^{\circ}$ ). Mas, se as concessões outorgadas pelo Estado têm uma natureza de direito real este direito não se assemelha a um direito de propriedade, somente a um direito de usufruto.

O usufrutuário "deve explorar o bem de acordo com a forma normal e costumeira" e se abster de fazer qualquer "modificação substancial em sua utilização". A questão é saber quais destes critérios são satisfeitos pelas modalidades indígenas de exploração.

Além disso, o art. 27 da Nova Lei das Comunidades Nativas dispõe que os povos indígenas têm prioridade na obtenção de contratos de exploração e extração florestais e de reflorestamento. Porém, nos casos de não cumprimento dos termos e condições da concessão, o "abandono" de terras é juridicamente adquirido. Ocorre que, estes termos e condições implicam, freqüentemente, na proibição à caça ou à pesca, mesmo que para subsistência ${ }^{(9)}$.

Acrescente-se que, de acordo com o art. 12 da Lei n. $27.308^{(10)}$, as comunidades nativas devem, antes de utilizar para fins comerciais os recursos florestais (madeireiros ou não) e da fauna silvestre, elaborar um Plano de Uso, o qual deve ser aprovado pelo Instituto Nacional de Recursos Naturais. Entretanto, antes disso, os povos precisam de uma permissão de uso (decreto de aplicação da nova lei florestal(11)), considerado prioritário.

\section{Incidências da distinção}

A diferenciação entre os regimes jurídicos (terra agrícola/florestal) pode ter pesadas conseqüências ambientais sobre as quais não houve uma reflexão acerca de suas adequações às características específicas dos ecosistemas amazônicos.

\footnotetext{
Nacionais podem ser exploradas apenas pelo Estado, enquanto as Florestas de Livre Disponibilidade podem ser exploradas legalmente por qualquer pessoa, mediante um Contrato de Cessão de Uso. Ver LUDESCHER, M. El régimen legal de los recursos naturales en el Perú y sus consecuencias para los pueblos indígenas de la Amazonía. In: KUPPE, R.; POTZ, R. (Dir.). Natural resources, environment and legal pluralism. Law and Anthropology, International Yearbook for Legal Anthropology. Kluwer Law International, 1997. v. 9, p. 238.

(8) Decreto-lei n. 21147, de 15 de maio de 1975.

(9) Ver AROCA, J. El indígena y las comunidades nativas en la Amazonía peruana. In: DEGREGORI,

C. I. (Dir.). Comunidades: tierra, instituciones, identidad. Lima: Diakonía; CEPES; Arawira,1998. p. 124.

(10) Nova Lei Florestal da Fauna Silvestre de 15 de julho de 2000.

(11) Decreto Supremo n. 014-2001-AG, de 4 de agosto de 2001.
} 
Dentro do modo de vida dos povos indígenas, a distinção entre terras agrícolas e florestais não faz sentido. Na concepção indígena de espaço, as terras não se distinguem em zonas produtivas de uso exclusivo para esta ou aquela determinada atividade. Entre outras razões, está o fato de que os indígenas fazem uso das terras de maneira cíclica e temporária, em virtude da pobreza do solo. Assim, não tem fundamento a proibição estatal de práticas não agrícolas em certas áreas, seja por questões ecológicas ou, a partir de uma abordagem agronômica, porque não há territórios disponíveis suficientes.

O problema é também jurídico. Os Shipibo, freqüentemente, fazem o reflorestamento das terras agrícolas, limitando assim ainda mais o espaço jurídico prescrito para as culturas. E, de modo inverso, eles cultivam alimentos nas terras florestais, tendo como conseqüência o "abandono" das terras, resultante do não cumprimento dos termos e condições do Contrato de Cessão e Uso(12).

\section{B. Bolívia: direitos prioritários; porém, sempre dependentes}

Na Bolívia, os direitos prioritários são, teoricamente, acordados com os indígenas. Contudo, na prática, estes povos devem negociar com as autoridades municipais, em razão de sua incapacidade de exercer seus direitos de maneira autônoma.

\section{Exclusividade e prioridade dos direitos}

O art. 32 da Lei Florestal de $1996^{(13)}$ garantiu aos povos indígenas (constituindo uma Organização Territorial de Base - OTB) a exclusividade de uso florestal das Terras Comunitárias Originais - TCO — legalmente reconhecidas, de acordo com o art. 171 da Constituição e da Convenção n. 169. Além disso, de acordo com 12a ${ }^{a}$. Disposição Final da Lei n. $1.715^{(14)}$, nas TCO onde exista "superposição ou conflito de direitos" prevalece o direito da comunidade indígena originária, em detrimento das concessões, contratos ou autorizações de utilização florestal. Todavia, é necessário analisar os limites dessas normas.

\section{A falta de um nível mínimo de usufruto dos recursos}

Segundo o art. 3(3) da Lei n. 1.715, os títulos das TCO outorgam como certa a propriedade coletiva destas terras, mas não outorgam um nível míni-

(12) Ver TUBINO ARIAS-SCHREIBER, F. Los Shipibo del río Ucayali: un pueblo en busca de sus derechos. In: DERECHOS humanos y pueblos indígenas de la Amazonía peruana: realidad, normativa y perspectivas. Lima: APEP; CAAAP, 1996. p. 176-177.

(13) Lei n. 1.700, de 12 de julho de 1996.

(14) Lei do Serviço Nacional de Reforma Agrária de 18 de outobro de 1996. 
mo de uso, gozo e disposição dos recursos naturais existentes. Apenas é reconhecido aos povos indígenas o direito de "participar do uso e desfrute sustentáveis" desses recursos.

O Estado pode sempre regulamentar o uso dos recursos pelos indígenas, mesmo que se trate de utilização para subsistência.

\section{Incapacidade jurídica dos indígenas}

As TCO não têm nenhum estatuto independente. Elas são fundalmente submetidas à jurisdição de uma ou várias municipalidades e são estas autoridades (e não as próprias comunidades indígenas) que recebem os lucros provenientes das concessões florestais situadas nas TCOs e que decidem pela utilização destes lucros ${ }^{(15)}$. Os indígenas sofrem assim de uma incapacidade jurídica parcial: eles são titulares dos direitos que são exercidos por outros.

\section{Brasil: direitos exclusivos; porém, algumas vezes, condicionados}

No Brasil, os recursos naturais localizadis em reservas indígenas pertencem a estes povos e existe uma relativa liberdade de exploração.

\section{Direitos originários}

Os direitos dos povos indígenas sobre suas terras são qualificados como originários e são intangíveis. De fato, a própria definição de "territórios indígenas" (tal como mencionada no art. 231 da Constituição Federal de 1988) inclui dois aspectos intimamente ligados à necessidade de exploração dos recursos naturais, sob pena de incoerência jurídica. Assim, constituem os territórios indígenas as terras "utilizadas para suas atividades produtivas" e as terras "de importância fundamental para a preservação dos recursos naturais necessários ao seu bem-estar".

Desta maneira, toda medida com o efeito de impedir os indígenas de perpetuar sua relação (tanto cosmológica, como produtiva) com a natureza é contrário à lei. No entanto, pode-se questionar a intensidade desta relação.

(15) Ver ASSIES, W. El constitucionalismo multiétnico en América Latina: el caso de Bolivia. In: ACTAS DEL 12. CONGRESO INTERNACIONAL DE DERECHO CONSUETUDINARIO Y PLURALISMO LEGAL, DESAFÍOS EN EL TERCER MILENIO, Arica, Chile, 2000. Derecho y Sociedad. Disponible sur: <www.alertanet.org $>$. 


\section{Exclusividade e liberdade no regime geral}

O art. 23 do Estatuto do Índio de 1973 dispõe que os direitos de usufruto assegurados aos indígenas ou silvícolas incluem o direito à propriedade $\mathrm{e}$ à utilização dos recursos naturais e de todos os usos e utilidades existentes nos terrritórios ocupados por estes povos. Estes direitos de usufruto incluem igualmente o direito a receber pelo produto de exploração econômica dos recursos. $\mathrm{O} \S 2^{\circ}$ do art. 23 garante expressamente o direito exclusivo dos indígenas de caçar e pescar nas zonas que ocupam. Em seguida, na esteira do Estatuto de 1973, o objetivo principal da Constituição de 1988 foi o de reconhecer juridicamente a dependência das comunidades indígenas de seu habitat natural. Pelo art. 231 da Constituição, o governo é obrigado a defender e a preservar, não apenas as terras habitadas pelos indígenas, como também todas as formas de uso de recursos naturais oriundas de suas atividades produtivas.

Todavia, o direito brasileiro não precisa uma maneira de conciliar dois imperativos, quais sejam: a preservação do uso dos recursos naturais pelos indígenas e a própria preservação natural(16). Pode-se pensar que a solução para esta questão pode ser encontrada conjuntamente com os indígenas, chamando-os a definir os limites de seus próprios direitos.

\section{Exclusividade e restrições no regime especial}

Esta liberdade dos povos indígenas quanto à escolha das modalidades de exploração não é a norma no que diz respeito aos recursos florestais.

$\mathrm{O}$ art. 46 do Estatuto do Índio dispõe que o corte de madeira nas florestas indígenas, sempre consideradas áreas de preservação permanente, é condicionado à existência de programas ou projeto de uso das terras destinadas à agricultura, pecuária, indústria ou reflorestamento.

De acordo com o art. ํ da Medida Provisória 1.956-55, de 19 de outobro de 2000, a exploração de recursos florestais em terras indígenas somente pode ser feita por estes povos e apenas para satisfazer suas "necessidades de subsistência", o que impede a exploração da madeira para fins comerciais. A exploração também deve ser sustentável, o que significa, realizada dentro do conceito de "utilização ou atividade sustentável da floresta".

A significação deste conceito é precisada, dentro da medida do possível, pelo Decreto - 2.788, de 19 de outubro de 1998, que trata da exploração

(16) Mais precisamente, se não há restrição à exploração dos recursos naturais por parte dos indígenas - desde que os produtos resultantes sejam consumidos pelas próprias comunidades, existem restrições em casos dos produtos serem destinados ao consumo externo às comunidades. Ver SANTILLI, J. Economic activities on indigenous peoples' lands. Instituto Socioambiental, 2001. Disponível em <www.socioambiental.org $>$. 
das florestas primárias do Baixo Amazonas. Seus objetivos principais são a conservação dos recursos naturais, a preservação da estrutura da floresta e de suas funções interdependentes, a manutenção da diversidade biológica e o desenvolvimento socioeconômico da região. Pode-se chegar a estes resultados com estudos das características ambientais, físicas e biológicas, a adoção de um sistema adequado de uso da floresta e com a garantia de execução técnica e econômica, assim como de benefícios sociais ${ }^{(17)}$.

Tanto no que concerne à realização dos objetivos quanto no que se refere à execução prática das técnicas, a participação dos indígenas, prevista pela Convenção n. 169 da Organização Internacional do Trabalho à qual são ligados os três países estudados, é uma condição de efetividade, tanto em termos de informação científica, como de legitimação política das medidas.

\section{PARTICIPAÇÃO DA ELABORAÇÃO DOS DIREITOS CIRCUNSTANCIAIS}

\section{A. Peru: falta de participação}

O direito peruano não prevê verdadeiramente a participação dos indígenas na elaboração das modalidades e limites de exploração dos recursos naturais.

\section{Reconhecimento e integração limitam as modalidades de gestão autóctone dos recursos}

Objetivando que a utilização dos recursos naturais pelo povos indígenas seja feita de maneira sustentável, o art. 29 do Decreto Legislativo n. 613 (1990) dispõe que o Estado deve oferecer apoio técnico às comunidades para a utilização, recuperação e conservação dos recursos ambientais. Ao mesmo tempo, deve "estimular o uso das tecnologias tradicionais ecologicamente adequadas". Porém, não existe a obrigação de que as autoridades formalize novas normas de utilização.

De qualquer modo, o art. 17 da Lei Orgânica que rege o uso dos recursos naturais prevê que "as formas ancestrais são reconhecidas, desde que elas não entrem em choque com as normas de proteção ambiental”.

(17) Ver PANKARARU, P. Forestry management on indigenous peoples' lands. Instituto Socioambiental, 2000. Disponível em <www.socioambiental.org>. 


\section{Em direção a uma codeterminação implícita das normas de gestão de recursos?}

A nova lei florestal não consagra explicitamente a participação dos indígenas na elaboração dos Planos de Uso.

No entanto, a partir de uma leitura conjunta do art. 89 da Constituição peruana de 1993 (segundo o qual as comunidades indígenas são "autônomas para usarem e livremente disporem de suas terras"), da Convenção n. 169 da Organização Internacional do Trabalho e das normas mencionadas acima, pode-se, no entanto, imaginar uma hipótese: os indígenas devem, pelo menos, poder participar do estabelecimento de normas com relação ao uso dos recursos naturais, conciliando suas necessidades e as exigências ambientais.

\section{Pistas para um zoneamento transitório e cíclico de terras}

A distinção entre terras agrícolas e florestais poderia ser legítima se fosse fundada em uma estratégia global de preservação da qualidade e da produção dos ecossistemas. E, poderia ser ainda mais pertinente, com a criação de uma zona transitória e de uso cíclico das terras que seguisse um plano de etnodesenvolvimento cuja realização seria concretizada pelos indígenas. Acrescente-se, a inscrição do direito de propriedade em princípios jurídicos co-determinados pelas comunidades e demais atores.

As terras de uso cotidiano seriam geridas diretamente pelas famílias (aquelas que desfrutam de um direito de usufruto particular de suas terras), em uma situação de vigilância da comunidade e dos organismos governamentais ou não-governamentais.

Enquanto isso, as terras de uso esporádico seriam geridas pelo conjunto da comunidade: nenhum direito de usufruto seria outorgado às famílias; porém, ações comunitárias poderiam ser realizadas para obter o máximo do potencial agronômico e ecológico das áreas.

\section{B. Bolívia: baixa participação}

Na Bolívia, a participação dos indígenas na elaboração de normas de exploração ambiental, tal como é prevista pela lei, limita, a priori, suas possibilidades e não permitem às comunidades a defesa contra eventuais explorações predatórias de suas terras.

\section{A dificuldade em elaborar os Planos de Uso Florestal}

Uma vez que a concessão florestal tenha sido acordada para o benefício dos indígenas (um caminho cheio de armadilhas), a determinação das 
formas de exploração é submetida a uma formalidade interessante que pode, porém, se revelar perigosa, considerando a pequena margem de manobra da lei permitida aos indígenas.

De acordo com o art. 28 do Regulamento Geral da Lei da Floresta(18), as comunidades devem elaborar um Plano de Uso Florestal ou devem "fazer parcerias" com profissionais e técnicos florestais e agrônomos. A legislação boliviana, no art. 28, dispõe que os Planos de Uso nas TCOs serão elaborados "considerando os processos de consulta participativa que levem em conta os usos e costumes dos povos indígenas e que incluam seus valores culturais e espirituais", sem mais nenhuma precisão.

$\mathrm{Na}$ realidade, a elaboração destes Planos depende, em grande parte, das forças econômicas que pressionam as comunidades a venderem a madeira. Assim, conforme os indígenas são estimulados a oficializarem seus direitos de exploração comercial de recursos naturais, eles falham ao não conseguirem estabelecer estratégias de exploração de longo prazo (ecológica e economicamente viáveis) em benefício de uma comercialização que atenda à demanda imediata ${ }^{(19)}$.

\section{Contexto jurídico limitante da margem de manobra dos indígenas}

Na falta de uma maior precisão legal com relação aos direitos indígenas de exploração ambiental, estas disposições relativas ao assunto devem ser lidas à luz das disposições gerais da legislação boliviana.

De um lado, o art. 171 da Constituição da Bolívia (1994), reconhecendo os direitos indígenas sobre as Terras Comunitárias de Origem, obriga ao uso sustentável dos recursos naturais. E é o Estado quem decide, unilateralmente, os critérios para julgar este uso.

De outro, o art. 56 da Lei Ambiental (1992) prevê que o Estado deva promover programas de desenvolvimento em favor das comunidades "que utilizam tradicionalmente os recursos da flora e da fauna silvestre para fins de subsistência, com o propósito de evitar sua depredação e de atender ao uso sustentável". Uma interpretação estrita mostra que o direito limita as intenções comerciais dos indígenas, considerando apenas a economia de subsistência.

(18) Decreto Supremo n. 24.453, de 21 de dezembro de 1996.

(19) O que faz parecer que a autoridade estatal ao aprovar o Plano também avaliza práticas de desenvolvimento não sustentável. Ver, por exemplo, o caso descrito por TOWNSEND, W. Holding on to the land: the long journey of the Sirionó Indians. In: WEBER, R. et al. (Eds.). Indigenous peoples and conservation organizations: experiences in collaboration. Biodiversity Support Program; WWF, p. 85. 
Todavia, de acordo com o art. 78 desta mesma lei, o Estado deve criar mecanismos e procedimentos para garantir "a participação das comunidades tradicionais e povos indígenas no processo de desenvolvimento sustentável e no uso racional dos recursos naturais renováveis, considerando suas particularidades sociais, econômicas e culturais, no meio onde se desenrolam suas atividades". O Estado deve igualmente garantir "a salvaguarda, difusão e uso" dos conhecimentos indígenas sempre com a participação das comunidades.

Esta última disposição parece ser interessante; porém, uma análise mais exaustiva da legislação boliviana mostra que existem limites para os povos indígenas. Primeiro, toda exploração (comercial ou não) deve ser imperativamente definida, pelas autoridades competentes, como sendo sustentável. Assim, não existe recurso que possa ser usado livremente pelos indígenas. Depois, mesmo que as comunidades respeitem estas prescrições, não há garantia de apropriação dos recursos naturais pelos indígenas, sendo esta apropriação partilhada com outros atores, como as municipalidades, freqüentemente dominadas por cidadãos pouco abertos aos indígenas (mesmo quando existem indígenas prefeitos ou membros dos conseIhos municipais $\left.{ }^{(20)}\right)$.

Nesta situação, os indígenas bolivianos estão entre dois extremos, sendo que seus caminhos não seguem, a priori, no sentido de um desenvolvimento social e ecologicamente sustentável.

Em certos casos, eles apenas podem explorar seu ambiente para sua simples subsistência. Em outros, desde que as autoridades Ihes permitam, eles podem elaborar um Plano de exploração de recursos naturais de curto prazo.

\section{Brasil: participação a ser definida}

\section{Compartilhamento do princípio de elaboração de projetos}

A partir de uma leitura conjunta da Medida Provisória de 2000 e do Decreto de 1998, a aprovação de atividades de exploração da madeira em terras indígenas necessita da apresentação, por parte da comunidade, de um Plano de Uso da Floresta, o qual deve ser aprovado pelo Instituto Brasi-

(20) Neste caso, o sistema de descentralização pode funcionar em benefício dos indígenas, quando existem um casamento entre a municipalidade (máxima autoridade política e jurídica), o Distrito Municipal Indígena ou a OTB (abaixo da municipalidade) e as TCOs. De fato, graças unicamente a esta aliança que os indígenas podem administrar por conta própria seus negócios e ter a palavra final no que concerne à exploração de suas terras e ao desenvolvimento de planos de uso florestal compatíveis com os projetos estatais. 
leiro do Meio Ambiente e dos Recursos Naturais Renováveis (Ibama) e pela Fundação Nacional do Índio (Funai). Este plano deverá sempre respeitar as áreas de preservação permanente determinadas legalmente, nas quais é proibida a exploração de recursos naturais.

De outro lado, o art. $2^{\circ}$ do Decreto n. 1.141 (1994) enuncia que a elaboração de projetos ambientais ou de apoio às atividades produtivas indígenas, que decorrem da responsabilidade da União, deve ser feita com a participação dos representantes da Funai e das comunidades indígenas implicadas.

\section{Exercício de direitos sobre os recursos naturais pelo prisma do direito de propriedade dos indígenas}

Dentro da definição de terras indígenas ${ }^{(21)}$, o art. 231 da Constituição brasileira pode, razoavelmente, estender o respeito aos usos, costumes e tradições indígenas ao próprio exercício dos direitos reais das comunidades sobre os recursos naturais localizados em seus territórios.

Em outros termos, os Planos de Uso da Floresta, ou qualquer projeto, devem, dentro de uma certa medida, integrar a repartição costumeira das atividades produtivas e não produtivas, assim como as diferentes zonas espaciais. A intangibilidade de certas atividades fundamentais aos povos indígenas, que estão relacionadas ao sagrado, devem ser reconhecidas ${ }^{(22)}$.

Pode-se assim considerar que em sua globalidade (Estatudo do Índio, Constituição de 1988, Decreto de 1998 e Medida Provisória de 2000), o direito brasileiro reconhece, de um lado, as formas indígenas de gestão de recursos naturais e, de outro, o direito das comunidades em participar das decisões oficiais sobre o tema.

\section{CONCLUSÃO}

Resta definir concretamente os princípios relativos à determinação de regras de gestão de recursos naturais, partindo-se do conhecimento dos povos indígenas sobre seus territórios, limitando a exploração e permitindo, por sua vez, um certo desenvolvimento(23).

(21) "São terras tradicionalmente ocupadas pelos índios as por eles habitadas em caráter permanente, as utilizadas para suas atividades produtivas, as imprescindíveis à preservação dos recursos ambientais necessários a seu bem-estar e as necessárias a sua reprodução física e cultural, segundo seus usos, costumes e tradições."

(22) Existe na Amazônia brasileira numerosos exemplos de projetos que praticam estes princípios.

(23) Ver FILOCHE, G. Ethnodéveloppement, développement durable et droit en Amazonie. Bruxelles: Bruylant, 2006. 

$\operatorname{tarefa}^{(24)}$.

De outro lado, pretendeu-se desenvolver uma metodologia para essa

Pode-se utilizar o conteúdo dos costumes indígenas (quanto ao que se pode cultivar, por exemplo). Porém, em certos casos, este conhecimento pode não estar adaptado a uma realidade e a uma necessidade.

Desde que seja possível, é o direito típico dos indígenas que deve conceber e realizar, de acordo com certos princípios intangíveis (co-determinados pelos indígenas, Estado e comunidade científica), o que deve ser feito para o desenvolvimento sustentável. O direito indígena deve ser assim, pelo menos, um continente. De acordo com os antropólogos do direito, as características principais deste direito são a reatividade e a flexibilidade.

O direito indígena pode assim oferecer uma possibilidade de elaborar normas adaptadas a um contexto e que evoluam dentro de circusntâncias ecológicas e de necessidades sociais, sempre dentro de um cenário predefinido que assegure uma certa estabilidade.

\section{REFERÊNCIAS BIBLIOGRÁFICAS}

AROCA, J. El indígena y las comunidades nativas en la Amazonía peruana. In: DEGREGORI, C. I. (Dir.). Comunidades: tierra, instituciones, identidad. Lima: Diakonía; CEPES; Arawira,1998.

ASSIES, W. El constitucionalismo multiétnico en América latina: el caso de Bolivia. In: ACTAS DEL 12. CONGRESO INTERNACIONAL DE DERECHO CONSUETUDINARIO Y PLURALISMO LEGAL, DESAFÍOS EN EL TERCER MILENIO, Arica, Chile, 2000. Derecho y Sociedad. Disponible sur: $<$ Www.alertanet.org $>$.

FILOCHE, G. Ethnodéveloppement, développement durable et droit en Amazonie. Bruxelles: Bruylant, 2006.

KARPE, P. Y a-t-il encore des collectivités autochtones en Guyane française?: d'une méconnaissance à une indifférence (?) Contribution au $1^{\text {er }}$ forum des élus amérindiens de Guyane (Awala-Yalimapo, 8 décembre 2001). Revue Juridique et Politique - Indépendance et Coopération, n. 2, mai/août 2002.

LUDESCHER, M. El régimen legal de los recursos naturales en el Perú y sus consecuencias para los pueblos indígenas de la Amazonía. In: KUPPE, R.; POTZ, R. (Dir.). Natural resources, environment and legal pluralism. Law and Anthropology, International Yearbook for Legal Anthropology. Kluwer Law International, 1997. v. 9.

(24) Ver FILOCHE, G. Ethnodéveloppement, développement durable et droit en Amazonie. Bruxelles: Bruylant, 2006. 
PANKARARU, P. Forestry management on indigenous peoples' lands. Instituto Socioambiental, 2000. Disponible sur: <www.socioambiental.org>.

SANTILLI, J. Economic activities on indigenous peoples' lands. Instituto Socioambiental, 2001. Disponible sur: <www.socioambiental.org>.

TOWNSEND, W. Holding on to the land: the long journey of the Sirionó Indians. In: WEBER, R. et al. (Eds.). Indigenous peoples and conservation organizations: experiences in collaboration. Biodiversity Support Program; WWF.

TUBINO ARIAS-SCHREIBER, F. Los Shipibo del río Ucayali: un pueblo en busca de sus derechos. In: DERECHOS humanos y pueblos indígenas de la Amazonía peruana: realidad, normativa y perspectivas. Lima: APEP; CAAAP, 1996.

VIMON, J. Commentaire: les aspects civils de l'avant-projet de 1984. In: MARTRES, J.-P; LARRIEU, J. (Dir.). Coutumes et droit en Guyane. Economica, 1993. 